\title{
Stage IIA Eyelid Carcinoma AJCC v8
}

National Cancer Institute

\section{Source}

National Cancer Institute. Stage IIA Eyelid Carcinoma A/CC v8. NCI Thesaurus. Code C140520.

Stage IIA includes: T2b-c, T3, N0, M0: T2b: Tumor measuring more than $10 \mathrm{~mm}$ but 20 $\mathrm{mm}$ or less in greatest dimension with invasion of the tarsal plate or eyelid margin. $\mathrm{T} 2 \mathrm{c}$ : Tumor measuring more than $10 \mathrm{~mm}$ but $20 \mathrm{~mm}$ or less in greatest dimension involving the full thickness of the eyelid. T3: T umor measuring more than $20 \mathrm{~mm}$ but $30 \mathrm{~mm}$ or less in greatest dimension. N0: No evidence of lymph node involvement. M0: No distant metastasis. (AJCC 8th ed.) 